\title{
Development and Validation of Estimation of Genotoxic Impurity (Hydroxylamine Hydrochloride Content) in Leflunomide by using RP-HPLC Technique
}

\author{
MOHAN BHATALE ${ }^{1,2}$, NEELAKANDAN KALIYAPERUMAL ${ }^{2}$, GOPALAKRISHNAN \\ MANNATHUSAMY ${ }^{2}$ and GURUNATHAN RAMALINGAM ${ }^{2 *}$
}

\begin{abstract}
'Department of Chemistry, Annamalai University, Annamalai Nagar, Chidambaram-6086 02, India. ${ }^{2}$ Analytical Research Centre, Emcure Pharmaceuticals Limited, Hinjawadi, Pune-4110 57, India. ${ }^{*}$ Corresponding author E-mail: drgr_dde@ $@$ rediffmail.com
\end{abstract} http://dx.doi.org/10.13005/ojc/370232

(Received: March 10, 2021; Accepted: April 11, 2021)

\begin{abstract}
A simple, selective, linear having accuracy and specific of reverse phase high-performance liquid chromatographic (RP-HPLC) method for determination of Genotoxic impurity, Hydroxylamine hydrochloride of drug Leflunomide is reported. The separation and analysis were done on YMC-Triart C18 $\left(4.6 \mathrm{~mm} \times 150 \mathrm{~mm}\right.$ ), having particle size $3.0 \mu \mathrm{m} . \mathrm{KH}_{2} \mathrm{PO}_{4}$ in $2000 \mathrm{~mL}$ of purified water and $2 \mathrm{~mL}$ triethylamine with $\mathrm{pH} 2.5$ with phosphoric acid is mobile phase- $\mathrm{A}$, while acetonitrile is mobile Phase- $\mathrm{B}$ with gradient program. The elution achieved with $1.50 \mathrm{~mL} / \mathrm{min}$ flow rate and using UV detection at 230 $\mathrm{nm}$ wavelength. Selected column oven temperature is $45^{\circ} \mathrm{C}$ and auto sampler $5^{\circ} \mathrm{C}$ respectively. In this method linearity and accuracy of Hydroxylamine hydrochloride covered with specification limit of LOQ to $150 \%$ (i.e.3 to $23 \mathrm{ppm}$ ). The observed correlation coefficient is 0.99965 and recovery in between 99.07 to 114.94 . In method precision (ie. repeatability) and intermediate precision (IP) observed \% RSD of six spiked test preparation is below $5.0 \%$. The standard and sample were stable for 3 days when stored at 2 to $8^{\circ} \mathrm{C}$ temperature. In robustness studies system suitability parameters ie tailing factor, theoretical plates and \%RSD does not show significant changes. The present RP-HPLC method is selective, robust, linear, and precise for detection of Hydroxylamine $\mathrm{HCl}$.
\end{abstract}

Keywords: Hydroxylamine hydrochloride, RP-HPLC, Stability indicating, Genotoxic impurity,

\section{INTRODUCTION}

Leflunomide (see Fig. 1) is an immunesuppressive ${ }^{1}$ disease-modifying anti-rheumatic drug (DMARD) and mainly use for treatment of active moderate-to-severe rheumatoid arthritis ${ }^{2,3}$ and psoriatic arthritis. The chemical name of Drug substance Leflunomide is a 4-Isoxazolecarboxamide,
5-Methyl-N-[4-(trifluromethyl)-phenyl]. It acts inhibitor of synthesis of pyrimidine which works by preventing dihydroorotate dehydrogenase. The molecular formula and molecular weight of Leflunomide is $\mathrm{C}_{12} \mathrm{H}_{9} \mathrm{~F}_{3} \mathrm{~N}_{2} \mathrm{O}_{2}$ and 270.21 respectively.

In manufacturing process, Leflunomide ${ }^{4}$ manufactured from starting material 4-(trifluromethyl)

This is an Open Access article licensed under a Creative Commons license: Attribution 4.0 International (CC- BY). Published by Oriental Scientific Publishing Company @ 2018 
aniline (TFMA) and 5-Methylisoxazole-4-carboxylic acid (5-MIA) respectively. In that of key starting material 5-MIA is shows the potential genotoxic agent. Therefore occurrence of this Hydroxylamine $\mathrm{HCl}$ impurity needs to investigate in the Leflunomide. In literature, no particular method is reported for the determination of Hydroxylamine hydrochloride content present in the Leflunomide. The aim of present study is to developing sensitive, cost effective, and validated RP-HPLC method for content of Hydroxylamine $\mathrm{HCl}$ impurity in Leflunomide.<smiles>Cc1oncc1C(=O)Nc1ccc(C(F)(F)F)cc1</smiles>

Fig. 1. Leflunomide Chemical structure

\section{MATERIALS AND METHOD}

The sample of Leflunomide and its impurity for Development and validation are received from Emcure pharmaceuticals Itd, R \& D, Hinjawadi, Pune. Analytical grade potassium dihydrogen phosphate, $\mathrm{Na}_{2} \mathrm{HPO}_{4} \cdot 2 \mathrm{H}_{2} \mathrm{O}$ and purified water (HPLC grade) used for mobile phase and diluent preparations. The acetonitrile and triethylamine used are of gradient grade. The 3,5-dinitobenzoyl chloride used in preparation of derivatized reagent. Analytical balance is used of make- metler Toledo and waters HPLC with UV/PDA detector and data acquisition, calculation with Chromeleon software. All the instruments calibrated before used.

\section{Mobile phase-A}

Homogeneous mixture containing $0.14 \%$ of $\mathrm{KH}_{2} \mathrm{PO}_{4}$ and triethylamine with $0.1 \%$ in water and adjust $\mathrm{pH} 2.5$ with phosphoric acid.

\section{Mobile Phase B}

Acetonitrile

\section{Diluent}

$0.05 \%$ hydrochloric acid in water is as diluents.

\section{Derivatized Reagent}

$0.17 \%$ solution by dissolving 3,5 Dinitrobenzoyl chloride in Acetonitrile.

\section{Buffer solution for derivatized}

Prepare $0.71 \%$ of $\mathrm{Na}_{2} \mathrm{HPO}_{4} \cdot 2 \mathrm{H}_{2} \mathrm{O}$ in water with $\mathrm{pH} 8.0$ with phosphoric acid.

\section{Standard and sample solutions}

Prepare standard solution $0.075 \mathrm{ppm}$ and sample solution with $5000 \mathrm{ppm}$. Then both taken in separate in a $15 \mathrm{~mL}$ centrifuge tube, to this add 2.0 $\mathrm{mL}$ buffer solution, $2.0 \mathrm{~mL}$ Standard and sample solution (separately) and $0.5 \mathrm{~mL}$ derivatized reagent, mix well and vortex up to 30 seconds.

\section{Method Development}

The Leflunomide and its impurity are polar in nature, therefore method of genotoxic Hydroxylamine hydrochloride is developed with reversed phase chromatography. Non-polar Stationary phase like C4, C8, C18 in RP-HPLC, while polar mobile phase as water, acetonitrile or buffer solution. During this development with respect to stationary, mobile phases other parameters i.e. column compartment temp, diluents, wavelength, and $\mathrm{pH}$ plays crucial role. During stationary phase screening from particular Hypersil BDS C18 and YMC Triart, both C18 having

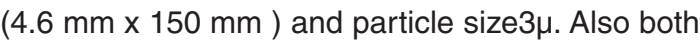
are showing availability with $150 \mathrm{~mm}$ and $250 \mathrm{~mm}$ length. When the YMC Triart of C18 (4.6 x 150 $\mathrm{mm}) 3 \mu$ is used found better separation of impurity, peak sharpness good having appropriate system suitability i.e. tailing factor, column efficiency.

Here $\mathrm{KH}_{2} \mathrm{PO}_{4}$ is used for preparation of mobile phase. Thus, homogeneous mixture of $0.14 \%$ of $\mathrm{KH}_{2} \mathrm{PO}_{4}$ and triethylamine $0.1 \%$ in water, kept $\mathrm{pH} 2.5$ with addition of $\mathrm{H}_{3} \mathrm{PO}_{4}$ and degas (Mobile Phase A) whereas the degased acetonitrile for mobile phase B. The tot run time of analysis is 40 minutes. The appropriate gradient program, flow rate, temp. of column oven, auto sampler temp. is selected by performing different trial runs of standard preparation. Table 1 shows details of chromatographic conditions.

Furthermore, the gradient program has been used to perform the HPLC analysis, the composition 60:40 of mobile phase $A$ and $B$ has been used initially, which modified to $30: 70$ for $23 \mathrm{~min}$ and maintain up to 28 minute. Finally, composition brought to initial value 60:40 in 1.0 min and maintain throughout the run i.e. up to 40 minute. 
Table 1: Content of Hydroxylamine hydrochloride impurity chromatographic condition for RP-HPLC

\begin{tabular}{ll}
\hline Component & Specification \\
\hline Apparatus & $\begin{array}{l}\text { HPLC with UV/PDA detector, injector, } \\
\text { pump, and recorder }\end{array}$ \\
& UV/PDA detector \\
Detector & YMC Triart C18 (150 X 4.6) mm, 3.0 $\mu$ \\
Column & 230 Nano meter \\
$\lambda$ max & $1.5 \mathrm{~mL} / \mathrm{min}$ \\
M.P flow & $1.0 \mathrm{micro}$ liter \\
Volume of Injection & $45^{\circ} \mathrm{C}$ \\
Column oven temp. & $5^{\circ} \mathrm{C}$ \\
Auto sampler temp. & $40 \mathrm{~min}$ \\
Run time &
\end{tabular}

\section{RESULTS AND DESCUSION}

This validation and development study was carried with reference as per IP, BP, USP and Q2 $(\mathrm{R} 1)^{5-8}$ of $\mathrm{ICH}$ guideline. The ICH guideline M7 (R1) ${ }^{9}$ utilized for finalization of specification limit based on duration of treatment and dose. The details of validation parameters are discussed below.

\section{Specificity}

Selectivity study parameter was performed by injecting Blank (diluent), standard (0.075 ppm hydroxylamine hydrochloride) and sample solution $(5000 \mathrm{ppm})$. The chromatograms are analysed at same wavelength mentioned in method. The specificity data given in to Table 2 and related chromatogram in Fig. 2. No interference of Blank (diluent) at retention time of hydroxylamine hydrochloride peak. In sample solution all known as well as unknown peaks are well separated from each other. The observed value of peak purity is higher than 950 , shows peak is pure.

Table 2: Data of specificity of hydroxylamine hydrochloride in Leflunomide

\begin{tabular}{|c|c|c|c|c|}
\hline \multirow[t]{2}{*}{ Impurities name } & \multicolumn{2}{|c|}{ Individual solution } & \multicolumn{2}{|c|}{ Spiked test preparation } \\
\hline & Retention time (minutes) & Peak purity & Retention time (minutes) & Peak purity \\
\hline TFMA & 23.901 & 970.1 & 23.875 & 1000 \\
\hline MIA & ND & - & ND & - \\
\hline $\mathrm{HCA}$ & 4.987 & 1000.0 & 4.960 & 1000.0 \\
\hline m-TLFM & 12.848 & 999.8 & 12.848 & 999.9 \\
\hline 3-LFM & 12.888 & 999.7 & & \\
\hline Hydroxylamine hydrochloride & 11.541 & 995.6 & 11.547 & 997.3 \\
\hline
\end{tabular}

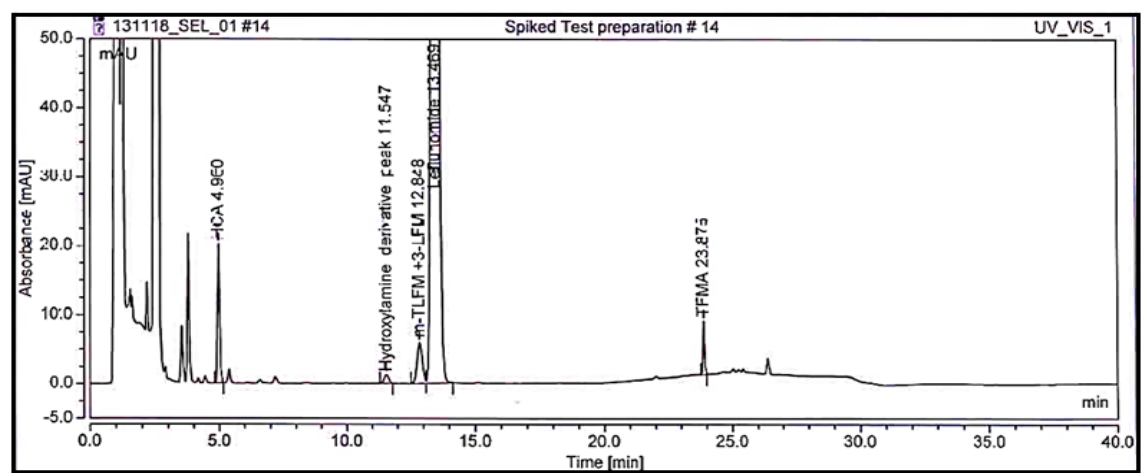

Fig. 2. Spiked Impurities in Leflunomide Typical chromatogram for Selectivity

\section{Limit of detection (LOD) and limit of quantitation}

Limit of detection and Limit of quantitation conc. of hydroxylamine hydrochloride impurity in Leflunomide was determined by applying signal-tonoise ratio method. To establish the predicted LOD concentration and LOQ concentration, injecting the various concentration levels (between 10 to $100 \%$ ) of standard solutions of hydroxylamine hydrochloride limit level concentrations. The predicted LOQ concentration value for hydroxylamine hydrochloride was $3.0 \mathrm{ppm}$. The LOD concentration evaluate by multiplying factor
0.33 to predicated LOQ concentration. The predicated LOD and LOQ values is shown in Table 3.

\section{Linearity and Range}

The linearity methods ability to get test results having proportional to its conc. of analyte in respective test sample. The linearity study carried out standard solutions of hydroxylamine hydrochloride with LOQ Level to $150 \%$ specification limit (encompassing 50, 80, 100, 120 and $150 \%$ ) of concentration. 
Table 3: LOD and LOQ data in hydroxylamine hydrochloride

\begin{tabular}{lllll}
\hline Name of Impurity & Conc. w.r.t test (in ppm) & \multicolumn{2}{c}{ s/n ratio } \\
& $\begin{array}{l}\text { LOQ } \\
\text { level }\end{array}$ & $\begin{array}{l}\text { LOD } \\
\text { level }\end{array}$ & $\begin{array}{l}\text { LOQ } \\
\text { level }\end{array}$ & $\begin{array}{l}\text { LOD } \\
\text { level }\end{array}$ \\
\hline $\begin{array}{l}\text { Hydroxylamine } \\
\text { hydrochloride }\end{array}$ & 3.0 & 1.0 & 22.0 & 5.0 \\
\hline
\end{tabular}

The correlation coefficient, slope, concentrations and intercept of linearity data are reported in Table 4 and linearity graph presented in Fig. 3. The peak area verses concentration data was analysed by least squares linear regression analysis. The correlation coefficient observed for Hydroxylamine hydrochloride is 0.99965 which is greater than 0.999 .

Table 4: Linearity data for the Hydroxylamine hydrochloride impurity (LOQ to $150 \%$ Concentration)

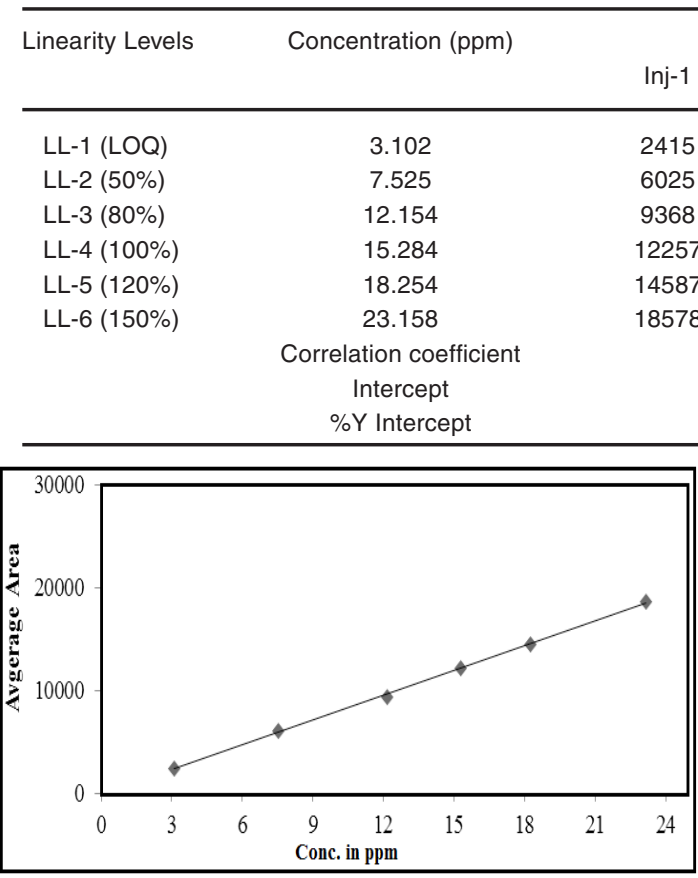

Fig. 3. Linearity graph for the Hydroxylamine hydrochloride impurity content from LOQ to $150 \%$ concentration range

\section{Precision}

System precision was performed by injecting five replicate of standard preparation as per mentioned in method of analysis. The observed percent RSD for replicate injections is 1.51 and tailing factor is 1.05. For Method precision six different sample prepared and analysed, And Intermediate precision six different sample preparations by different day, different system, and different column and analysed. In method precision and Intermediate precision observed \%RSD is 1.40 and 1.66 respectively. For twelve test preparations (six from method precision and six from intermediate precision) Overall \%RSD is 1.46 , which is less than $5.0 \%$. Method precision and intermediate precision results are tabulated in Table 5.
Peak area

$\begin{array}{ccc}\text { Inj-2 } & \text { Inj-3 } & \text { Average }(n=3) \\ 2358 & 2489 & 2421 \\ 6154 & 6045 & 6075 \\ 9457 & 9365 & 9397 \\ 12184 & 12184 & 12208 \\ 14379 & 14496 & 14487 \\ 18657 & 18760 & 18665 \\ & & 0.99965 \\ & & 125.8423 \\ & & 1.03\end{array}$

Table 5: Hydroxylamine hydrochloride impurity result of method and intermediate precision

\begin{tabular}{|c|c|c|}
\hline \multirow{2}{*}{$\begin{array}{l}\text { Spiked sample } \\
\text { solutions }\end{array}$} & \multicolumn{2}{|c|}{$\%$ of Hydroxylamine $\mathrm{HCl}$ impurity (in ppm) } \\
\hline & Method Precision & Intermediate Precision \\
\hline Preparation -1 & 15.3211 & 14.7652 \\
\hline Preparation -2 & 14.9423 & 15.2312 \\
\hline Preparation -3 & 15.0180 & 15.3412 \\
\hline Preparation -4 & 15.2010 & 14.9342 \\
\hline Preparation -5 & 15.1230 & 15.2242 \\
\hline Preparation -6 & 14.7162 & 14.7812 \\
\hline Mean & 15.0536 & 15.0462 \\
\hline SD & 0.21 & 0.25 \\
\hline RSD & 1.40 & 1.66 \\
\hline \multicolumn{2}{|c|}{ Overall Mean $(n=12)$} & 5.0499 \\
\hline \multicolumn{2}{|c|}{ Overall SD $(n=12)$} & 0.22 \\
\hline \multicolumn{2}{|c|}{ Overall\% $\operatorname{RSD}(n=12)$} & 1.46 \\
\hline
\end{tabular}

\section{Accuracy}

Accuracy of method was determined by spiking test preparation with impurity at $\mathrm{LOQ}$ Level, $50 \%$ level, 100 and $150 \%$ of specification limit concentrations. The \%accuracy data of hydroxylamine hydrochloride is presented in Table 6. The observed \% accuracy at LOQ Level and 50\% level, 100 and $150 \%$ is between 94.23 to $114.36 \%$ which is within acceptance criteria. (Accuracy should be between 70 to $130 \%$ )

\section{Robustness}

The method robustness verified by altering flow rate by $\pm 10 \%$. Original flow rate of $1.5 \mathrm{~mL} / \mathrm{min}$ is altered as $1.35 \mathrm{~mL} / \mathrm{min}$ and $1.65 \mathrm{~mL} /$ minute. The column oven temp. is changed with $\pm 5^{\circ} \mathrm{C}$ from $40^{\circ} \mathrm{C}$ in actual method. The observed area, standard 
deviation and its \%RSD are listed in Table 7. In all above study the retention times are varied by \pm 0.2 mins compared to original retention times. System suitability parameter obtained as tailing factor 1.01 to 1.15 and theoretical plates as 18433 to 20455 . The \%RSD for robustness studies are from 1.23 to 2.50 . The results in Table 6 indicated that change in method parameters (flow rate and column oven temperature), will no significant impact on system suitability criteria tailing factor, theoretical plates and \%RSD. The obtained results are well within acceptance limit.

Table 6: The \% accuracy data of hydroxylamine hydrochloride impurity

\begin{tabular}{lcccc}
\hline Tests & $\begin{array}{c}\text { LOQ } \\
\text { Level }\end{array}$ & $\begin{array}{c}50 \% \\
\text { Level }\end{array}$ & $\begin{array}{c}100 \% \\
\text { Level }\end{array}$ & $\begin{array}{c}150 \% \\
\text { Level }\end{array}$ \\
\hline Preparation-1 & 111.51 & 99.86 & 101.71 & 100.72 \\
Preparation-2 & 114.36 & 99.50 & 94.25 & 97.92 \\
Preparation-3 & 108.94 & 103.71 & 101.25 & 101.84 \\
$\quad$ Mean & 111.60 & 101.02 & 99.07 & 100.16 \\
SD & 2.71 & 2.33 & 4.18 & 2.02 \\
\%RSD & 2.43 & 2.31 & 4.22 & 2.02 \\
\hline
\end{tabular}

Table 7: Retention time, Theoretical plates, Tailing factor, and RSD of Robustness study for the hydroxylamine hydrochloride

\begin{tabular}{|c|c|c|c|c|}
\hline \multirow[t]{3}{*}{ System suitability parameters } & \multicolumn{4}{|c|}{ Hydroxylamine Hydrochloride } \\
\hline & \multicolumn{2}{|c|}{ Mobile phase Flow rate } & \multicolumn{2}{|c|}{ Column oven temperature } \\
\hline & $1.35 \mathrm{~mL} / \mathrm{min}$ & $1.65 \mathrm{~mL} / \mathrm{min}$ & $35^{\circ} \mathrm{C}$ & $45^{\circ} \mathrm{C}$ \\
\hline Retention time & 12.836 & 12.645 & 12.818 & 12.798 \\
\hline Tailing factor & 1.15 & 1.09 & 1.01 & 1.08 \\
\hline Theoretical plates & 19785 & 18433 & 19125 & 20455 \\
\hline$\% R S D(n=6)$ replicate of standard preparation & 2.50 & 1.99 & 1.23 & 2.01 \\
\hline
\end{tabular}

\section{Solution Stability}

Solution stability of test preparation was performed at the 2 to $8^{\circ} \mathrm{C}$ temp. on the day basis up to 3 days. Cumulative \%RSD values of Hydroxylamine hydrochloride are well within acceptance criteria up to 1 day. This indicates that Analytical test preparations is stable for 1 day, when stored at 2 to $8^{\circ} \mathrm{C}$ temperature.

\section{Mobile phase stability}

Mobile phase prepared as per method of analysis and performed analysis. After completion of analysis store a mobile phase at room temperature and demonstrate mobile phase stability. Check and compared system suitability parameter initial analysis and mobile stability study analysis. The \%RSD and change in retention time in standard hydroxylamine hydrochloride is within criteria and no haziness, precipitation and appearance of mobile phase is observed up to $60 \mathrm{hrs}$. Hence at room temperature mobile phase stability is 60 hours.

\section{CONCLUSION}

RP-HPLC method of hydroxylamine hydrochloride content analysis of Leflunomide is highly precise, selective, accurate with stability indicating and as per the ICH guidelines Q2(R1) is developed accurately and successfully validated. The specificity shows that, Hydroxylamine peak is fully resolved from known as well as unknown impurities. Method is linear with LOQ to $150 \%$ level w.r.t specification concentration and observed Correlation coefficient is 0.99965 . The recovery of Hydroxylamine hydrochloride was achieved between 94.23 to $114.60 \%$. In Robustness study system suitability like tailing factor, theoretical plates and \%RSD does not show significant impact. The observed results found within acceptable limits. The validated method shows satisfactory data for all tested method parameters. Hence present method specific, linear, selective, precise robust, as well as stable and can effectively useful in analysis.

\section{ACKNOWLEDGEMENT}

The author expresses gratitude to Dr. Mukund Gurjar, Emcure Pharmaceuticals Ltd, Analytical Research Centre(ARC), Hinjawadi, Pune for their valuable support encouragement and approving this work to communication for journal.

\section{Conflict of interest}

Conflict of interest declared none. 


\section{REFERENCES}

1. Anthony C. A. Immunosuppressive drugs: the first 50 years and a glance forward, Immunopharmacology., 2000, 47, 63-83.

2. Reuben A. Hepatotoxicity of Immunosuppressive Drugs. In: Kaplowitz N, Deleve L., eds. Drug-Induced Liver Disease ( $3^{\text {rd }}$ ed). New York; Academic Press., 2013, 569-591.

3. Li E.; Tam L.; Tomlinson B. Leflunomide in the treatment of rheumatoid arthritis. Clin Ther., 2004, 26, 447-459.

4. Rx list, Leflunomide description., 2007.

5. ICH guidelines; Q8 (R2), Harmonised Tripartite Guideline, on Pharmaceutical development, Proceedings of the International Conference on Harmonization., 2009.

6. ICH guidelines; Q3A (R2), Impurities in new drug substances, in: International Conference on Harmonization, Geneva., 2006.

7. $\quad \mathrm{ICH}$ guidelines, Q1A (R2); Stability Testing of New Drug Substances and Products, International Council for Harmonization Geneva. (http://wwwichorg/products/ guidelines/quality/article/quality-guidelines/ html)., 2003.

8. $\mathrm{ICH}$ guidelines, Q2 (R1): Validation of Analytical Procedures: Text and Methodology, International Conference on Harmonization Geneva. (http://wwwichorg/products/ guidelines/quality/article/quality-guidelines/ html)., 2005.

9. $\quad \mathrm{ICH}$ guideline $\mathrm{M} 7(\mathrm{R} 1)$ on assessment and control of DNA reactive(mutagenic) impurities in pharmaceuticals to limit potential carcinogenic risk., 2018. 